\section{СПИСОК ЛИТЕРАТУРЫ:}

1. Станковский А. Экологические проблемы водных ресурсов. Омск: Наука, 2004. 183 с.

2. Шикломанов И.А. Водные ресурсы России и их использование. СПб.: Государственный гидрологический институт, 2008. 152 с.

3. Балков А.В. Водные ресурсы Башкирии. Уфа: Просвещение, 2008. 355 с.

4. Гареев А.М. Реки и озера Башкортостана. Уфа: Китап, 2011. 259 с.

5. Гареев А.М. Водные ресурсы Башкирии и их состояние в будущем. Уфа: Китап, 2003. 204 с.

6. Миннигалиев Н.Х. Край родной, навек любимый. Уфа: Китап, 2011. 358 с.

7. ГОСТ 31861-2012 Вода. Общие требования к отбору проб. М.: Стандартинформ, 2013. 32 с.

8. Санитарные правила и нормы СанПиН 2.1.5.980-00 «Гигиенические требования к охране поверхностных вод». Утв. главным государственным санитарным врачом РФ Г.Г. Онищенко 22.06.2000 г.

9. Машкин П.В. Биологические методы оценки состояния водных экосистем. Омск: Наука, 1996. 34 с.

10. Коробейникова Л.А. Комплексная экологическая практика школьников и студентов: учебнометодическое пособие. СПб., 2002. 268 с.
11. Хараева Г.И. Экологический мониторинг. УланУдэ: Изд-во ВСГТУ, 2004. 77 с.

12. Черкесова Д.У., Шахназарова А.Б. Экология животных. Махачкала: Юг России, 1990. 131 с.

13. Ажипа Я.И., Реутов В.П., Каюшин П.П. Экологические и медико-биологические аспекты проблемы загрязнения окружающей среды нитратами и нитритами // Физиология человека. 1990. Т. 16, № 3. С. $131-150$.

14. Велдре И.А.Токсическое воздействие нитратов на рыб. Экология 1990. С. 71-73.

15. Логинова Е.В., Лопух П.С. Гидроэкология. Мн.: БГУ, 2011. $78 \mathrm{c.}$

16. Абдрахманов Р.Ф., Попов В.Г. Ионообменная концепция в генетической гидрохимии. Уфа: Гилем $2013.357 \mathrm{c}$.

17. Москвин А.Г. Экология водоемов России. Рязань: Школа-Пресс, 1999. 134 с.

18. Сибагатуллина А.М., Мазуркин П.М. Измерение загрязненности речной воды. М.: Изд-во «Академия естествознания», 2009. 216 с.

19. Абдрахманов Р.Ф. Гидрогеоэкология Башкортостана. Уфа: Информ, 2005. 344 с.

20. Акимушкин И.И. Мир животных: Беспозвоночные. М.: Мысль, 1992. 382 с.

\title{
ECOLOGICAL CONDITION OF THE SMALL RIVERS IK AND SYUN IN THE SHARANSKY DISTRICT OF THE REPUBLIC OF BASHKORTOSTAN
}

\author{
Nafikova Elvina Rishatovna, master student of Biology and Ecology Department \\ Islamova Aysylu Airatowna, candidate of biological sciences, \\ associate professor of Biology and Ecology Department \\ Birsk branch of Bashkir State University (Birsk, Republic of Bashkortostan, Russian Federation)
}

Abstract. Currently the negative impact of man on aquatic ecosystems is very noticeable. This, in the final analysis, was reflected in the change in the hydrological regime of rivers and lakes. Environmental conditions in many water bodies deteriorated sharply. There are also acute exacerbations of water management situations, deterioration of water use conditions due to the lack of scientifically based principles of nature management in the catchment area, and quantitative and qualitative depletion of water resources due to the combined impact of various sectors of the national economy The ecological state of water bodies largely depends on external influences, the magnitude of which should not exceed the permissible limits. In this case, the ecosystem maintains its stability. The paper deals with the assessment of the ecological state of rivers and their resistance to polluting effects, in particular, an assessment of the quality of the water of the Ik and Syun rivers in the Sharansky District of the Republic of Bashkortostan. Physicochemical and organoleptic analyses of the rivers have been carried out. The research was conducted in SeptemberMay 2016-2017. The analysis of the water was carried out in the analytical laboratories of the Tuimazy inter-district branch of the FBU «Center for Hygiene and Epidemiology in the Republic of Bashkortostan». The water quality in the river was estimated using the Mayer index.

Keywords: ecological condition of rivers; river Ik; Syun River; Belaya River; Sharansky District; Republic of Bashkortostan; Mayer index; maximum permissible concentration; biological oxygen consumption; chemical oxygen consumption: physical and chemical analysis; route-forwarding; organoleptic analysis; aquatic ecosystems; surface waters; hydrobionts.

УДК 598.112:591.16:591.13

Статья поступила в редакцию 03.10.2017

\section{ОТДЕЛЬНЫЕ АСПЕКТЫ БИОЛОГИИ ТАКYDROMUS WOLTERI И TAKYDROMUS AMURENSIS} (C) 2017

Портнягина Екатерина Юрьевна, аспирант кафедры экологии Дальневосточный федеральный университет (2. Владивосток, Российская Федерация)

Маслова Ирина Владимировна, кандидат биологических наук, ведущий инженер лаборатории териологии Федеральный научный иентр биоразнообразия наземной биоть Восточной Азии ДВО РАН

(2. Владивосток, Российская Федерация)

Аннотащия. В работе представлены сведения об отдельных аспектах размножения и питания двух малоизученных видов ящериц рода Takydromus - Takydromus wolteri u Takydromus amurensis - в северновосточной части их ареала (Приморский край, Дальний Восток, Россия). Использованный в публикации ма- 
териал был собран как в природных, так и в лабораторных условиях. Для обоих видов представлены данные по количеству и размерам яиц (в кладках) и сеголеток (сразу после выхода). Впервые в природе зафиксирована совместная кладка нескольких самок T. amurensis - 30 яиц. Впервые приводятся данные по срокам инкубационного периода для российских популяций этих видов: у T. amurensis - 44-56 дней, у T. wolteri - 4244. Отмечены более ранние, чем указывалось в литературных источниках, сроки выхода из яиц сеголеток T. wolteri - середина второй декады августа. Рассматриваются вопросы клинальной изменчивости по отдельным морфометрическим и репродуктивным параметрам. Выявлено, что оба вида в лабораторных условиях выбирают в качестве корма беспозвоночных из следующих отрядов и семейств: Aranei, Geophilomorpha, Lithobiomorpha, Tenebrionidae (larve), Muscidae, Ectobiidae и Gryllidae. Приводятся новые сведения по пищевому поведению T. wolteri $u$ T. amurensis в условиях террариума. Отмечено, что оба вида используют различные приёмы умерщвления и поедания добычи в зависимости от того, к какой группе беспозвоночных она относится. Экспериментальным путем доказано, что сеголетки T. amurensis могут принимать пищу уже через 2-3 часа после выхода из яиц.

Ключевые слова: Lacertidae; Takydromus wolteri; Takydromus amurensis; репродуктивные особенности; лабораторная инкубация; инкубационный период; размер яиц; количество яиц; размер сеголеток; количество сеголеток; клинальная изменчивость; пищевая избирательность; пищевое поведение; Приморский край; Дальний Восток; Россия.

\section{Введение}

Большая часть видов рода Takydromus (сем. Lacertidae, отр. Squamata) обитает в субтропическом и тропическом поясах [1], и только корейская (Takydromus wolteri Fischer, 1885) и амурская (Takydromus amurensis Peters, 1881) долгохвостки встречаются в умеренной климатической зоне. Северная граница их распространения проходит по территории Дальнего Востока России, а именно по Приморскому краю [2].

T. amurensis и T. wolteri менее изучены, чем другие виды дальневосточных пресмыкающихся, что связано с их малой численностью и скрытным образом жизни [3]. В литературе имеется незначительное количество работ по отдельным вопросам биологии и экологии этих видов. Первые наблюдения за T. wolteri еще в 1926 г. проводил в Маньчжурии П.А. Павлов, который описал некоторые особенности поведения этих ящериц в террариуме и их предпочтения в питании [4]. Достаточно подробно в 70-80-е годы прошлого столетия исследовал многие аспекты биологии T. amurensis Ю.М. Коротков [5; 6]. В своих работах он представил данные о распространении и биологии выше указанного вида: о его репродуктивных особенностях, сроках спаривания, особенностях размножения в лабораторных условиях, о его пищевых объектах. Но у Ю.М. Короткова практически отсутствует информация по второму виду. К тому же периоду времени относятся работы S. Takenaka [7] по репродуктивной экологии различных ящериц, обитающих на территории Японии, включая T. атиrensis. Есть некоторые упоминания о биологии T. amurensis и T. wolteri в обобщающей сводке по ящерицам этого рода у U. Schluter [8]. В середине 2000-х годов свои наблюдения за отдельными моментами поведения T. wolteri опубликовала И.В. Маслова [9]. В последнее десятилетие ряд работ по изучению биологии Takydromus был выполнен исследователями из Китая - L. Luo et al. [10] и B.J. Sun et al. [11] и Республики Корея - K.-S. Koo et al. [12]. Таким образом, для российской территории по биологии ящериц рода Takydromus имеются некоторые данные только по T. amurensis [5; 6] и совсем незначительные отрывочные сведения по T. wolteri [6; 9].

C учетом вышесказанного, настоящая работа направлена на получение новых сведений об отдельных аспектах биологии двух малоизученных видов ящериц рода Takydromus - Takydromus wolteri $u$
Takydromus amurensis - в северно-восточной части их ареала (Приморский край, Дальний Восток, Россия).

\section{Материалы и методы}

Полевые и лабораторные исследования по изучению репродуктивной биологии выполнялись нами в отдельные периоды времени с 1998 по 2016 гг. и носят фрагментарный характер.

Кладки яиц и выход сеголеток ящериц рода Takydromus фиксировались на полевых учетных маршрутах в нескольких районах Приморского края: Уссурийском, Надеждинском, Партизанском и в окрестностях г. Арсеньев в 1998, 2005, 2013, 2015 гг.

Наблюдения по размножению и питанию двух видов ящериц рода Takydromus в неволе выполнялись в 2005-2006 гг., 2009-2010 гг., 2015 г.

Для лабораторных исследований в окрестностях г. Арсеньев (Приморский край) было отловлено 8 беременных самок $(4-T$. amurensis и $4-T$. wolteri). После отлова самок содержали до момента откладки яиц в террариумах из стекла с размером дна $40 \times 20$ см и высотой 30 см без специального подогрева, при естественном освещении и температуре (от $19^{\circ} \mathrm{C}$ - в ночное время до $26^{\circ} \mathrm{C}$ - в дневное время). В качестве подстила использовались: земельный субстрат, мох (сфагнум) и куски коры дерева, насыпанные слоем в 5 см. Кладки помещались в отдельный пластиковый садок диаметром $10 \mathrm{~cm}$ и высотой $11 \mathrm{~cm}$, где проходила инкубация при постоянном увлажнении земельного субстрата и поддержании температурного режима в диапазоне (от $19^{\circ} \mathrm{C}-$ в ночное время до $26^{\circ} \mathrm{C}$ - в дневное время).

Bсе промеры выполнялись с помощью электронного штангенциркуля. У ящериц измерялись: длина головы (L.c.), ширина головы (Lt.c.), длина тела (L), длина хвоста (L.c.d). Причем у сеголеток эти промеры проходили в день их выхода из яйца. Промеры яиц заключались в измерении длины (L.ov) и ширины (Lt.ov) каждого яйца в день их откладки. Математическая обработка данных проведена общепринятыми методами с использованием программ MS Excel и пакета «Statistica».

Спектр питания обоих видов изучался в лабораторных условиях путем подбора для ящериц различных групп беспозвоночных, определение которых выполнялось по определителю А.К. Бродского и др. [13] до семейства и, в отдельных случаях, до отряда или подотряда сем. Lumbricidae, сем. Formicidae, сем. 
Портнягина Е.Ю., Маслова И.В.

Staphylinidae, сем. Tenebrionidae (larve), сем. Muscidae, сем. Ectobiidae, сем. Gryllidae, подотр. Oniscidea, отр. Aranei, отр. Geophilomorpha. Пищевые объекты отлавливались в окрестностях г. Арсеньев и г. Владивосток. Проводились наблюдения за пищевым поведением 5 особей Takydromus $(2-T$. amurensis и 3 T. wolteri).

\section{Результаты исследования и их обсуждение}

Во время учетных полевых работ в естественных условиях обитания было найдено 5 кладок обеих видов долгохвосток (2 кладки - T. wolteri и 3 - T. атиrensis). У T. wolteri обе кладки были найдены на дачных участках в окрестностях г. Арсеньев: первая 07.07.2005 г. в компостной куче (5 яиц) и вторая 04.09.2005 г. в огородной почве (2 яйца). Кладки T. amurensis были обнаружены в разных районах юга Приморского края: первая - 22.07.1998 г. под камнем у обочины лесной дороги (5 яиц) в окрестностях с. Каймановка Уссурийского района; вторая 19.08.2015 г. в песчаной почве на берегу горной реки (6 яиц) на пойменном участке среднего течения p. Малая Ананьевка Надеждинского района и третья - 10.08.2015 г. общая кладка от нескольких самок в количестве 30 яиц, закопанная в опилки мусорной кучи, в окрестностях с. Бровничи Партизанского района. Это первая совместная кладка нескольких самок T. amurensis, зафиксированная в природе.

В лабораторных условиях откладка яиц у различных особей T. amurensis была достаточно растянута и проходила со второй половины мая по вторую половину августа, а у T. wolteri она выполнялась в более сжатые сроки - со второй половины июня до второй половины августа. Одна самка T. amurensis откладывала от 4 до 7 яиц, в среднем - 5,2 (n=4), а

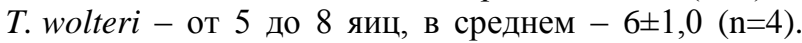
Средний размер тела у самок T. amurensis, отложив-

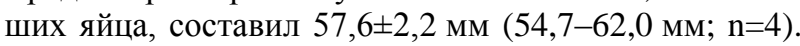
Для T. wolteri полученное среднее значение длины тела самок равнялось 54,7 $\pm 2,4$ мм (48,0-58,2 мм; $\mathrm{n}=4)$.

За все время наблюдений в инкубаторе содержалось 4 кладки T. amurensis и $4-T$. wolteri. У четырех самок T. amurensis из 14 суммарно отложенных яиц вышло 7 сеголеток, причем в одной кладке, самой ранней и отложенной в мае, развитие всех яиц замерло на ранних стадиях $(\mathrm{n}=7)$. У четырех самок T. wolteri из 12 отложенных яиц вышло 7 сеголеток и также полностью прекратилось развитие одной кладки $(\mathrm{n}=5)$. Длительность инкубации одной кладки для T. amurensis в лабораторных условиях варьировала от 44 до 56 дней $(\mathrm{n}=3)$, для T. wolteri - 42-44 дня $(\mathrm{n}=3)$. Информация по срокам инкубации яиц T. атиrensis в лабораторных условиях отсутствует в литературе и впервые приводится в этой работе.

Средний размер яиц у T. wolteri $(9,5 \pm 0,4 \times 5,9 \pm 0,1)$ был меньше, чем у $T$. amurensis $(10,6 \pm 0,1 \times 6,8 \pm 0,1)$. Полученные значения для T. amurensis и T. wolteri попадают в интервал значений, полученный Ю.М. Коротковым $(9 \times 8-12,5 \times 6,5-T$. amurensis, $9,1 \times 6,3-$ $10,0 \times 7,7-T$. wolteri) [6]. Форма яиц у обоих видов была одинаковой - овальной. Цвет яиц у первого вида с желтоватым оттенком, тогда как у второго - белый. Характеристика размеров и форм яиц приведена в табл. 1.
Таблица 1 - Размерный ряд, форма и окрас яиц T. amurensis и T. wolteri

\begin{tabular}{|l|c|c|}
\hline \multicolumn{1}{|c|}{ Характеристики } & T. wolteri & T. amurensis \\
\hline $\mathrm{N}$ & 12 & 14 \\
\hline L.ov.: & $8,0-10,9$ & $10,1-11,2$ \\
\hline - min-max & $9,5 \pm 0,4$ & $10,6 \pm 0,1$ \\
\hline - M \pm m (мм) & $5,4-6,6$ & $6,1-7,2$ \\
\hline Lt.ov.: & $5,9 \pm 0,1$ & $6,8 \pm 0,1$ \\
\hline - min-max & $\begin{array}{c}\text { Яйца овальные, } \\
\text { цвет слегка жел- } \\
\text { товатый }\end{array}$ & $\begin{array}{c}\text { Яйца оваль- } \\
\text { ные, цвет бе- } \\
\text { лый }\end{array}$ \\
\hline $\begin{array}{l}\text { Форма и окраска (мм) } \\
\text { яиц }\end{array}$
\end{tabular}

Примечание. $N$ - количество яиц, L.ov. - длина яйца, Lt.ov. - ширина яйца, $M$ - среднее значение, $m$ - ошибка среднего.

В природных условиях выход первых сеголеток T. amurensis зафиксирован 10.08.2015 г. (окрестности c. Бровничи, Партизанский район), а у T. wolteri 25.08.2013 г. (окрестности г. Арсеньев).

В инкубаторе у обоих видов начало выхода первых сеголеток из кладок, отложенных в конце июня, приходилось на середину августа. Кроме того, один раз было зафиксировано появление сеголеток у T. wolteri в конце первой декады сентября, из кладки, изъятой из природных условий 06.09.2005 и далее помещенной в инкубатор.

Наши данные по срокам выхода сеголеток T. wolteri указывают на более обширный временной диапазон, чем ранее указывалось в литературных источниках [6]. Так, выход из яиц сеголеток этого вида как в природе (25.08.2005), так и в лабораторных условиях (16.08.2009 г.) начинался уже с августа, а не с середины сентября, как указывал Ю.М. Коротков [6].

Длина тела новорожденных особей T. amurensis изменялась в диапазоне 23,9-25,3 мм, T. wolteri 21,0-22,5 мм. Данные по характеристике размеров вылупившихся сеголеток T. amurensis и T.wolteri представлены в табл. 2.

Таблица 2 - Размеры сеголеток T. amurensis и T. wolteri

\begin{tabular}{|c|c|c|}
\hline Характеристики & T. amurensis & T. wolteri \\
\hline $\mathrm{N}$ & 7 & 7 \\
\hline \multicolumn{3}{|l|}{ L.c.: } \\
\hline$-\min -\max$ & $6,8-7,5$ & $6,3-7,6$ \\
\hline$-\mathrm{M} \pm \mathrm{m}(\mathrm{MM})$ & $7,1 \pm 0,1$ & $6,9 \pm 0,2$ \\
\hline \multicolumn{3}{|l|}{ Lt.c.: } \\
\hline$-\min -\max$ & $3,7-4,2$ & $3,0-3,9$ \\
\hline$-\mathrm{M} \pm \mathrm{m}(\mathrm{MM})$ & $3,9 \pm 0,1$ & $3,6 \pm 0,1$ \\
\hline \multicolumn{3}{|l|}{$\mathrm{L}:$} \\
\hline$-\min -\max$ & $23,5-25,3$ & $21,0-25,1$ \\
\hline$-\mathrm{M} \pm \mathrm{m}(\mathrm{MM})$ & $24,6 \pm 0,3$ & $22,7 \pm 0,6$ \\
\hline \multicolumn{3}{|l|}{ L.c.d.: } \\
\hline$-\min -\max$ & $35,0-45,4$ & $32,5-45,3$ \\
\hline$-\mathrm{M} \pm \mathrm{m}(\mathrm{Mм})$ & $40,4 \pm 1,5$ & $37,0 \pm 2,0$ \\
\hline
\end{tabular}

Примечание. $N$ - количество сеголеток, L.c. длина головы, Lt.c. - ширина головы, $L$ - длина тела, L.c.d. - длина хвоста, $M$ - среднее значение, $m$ ошибка среднего.

Сравнительно недавно китайские исследователи провели ряд работ по изучению клинальной (геогра- 
фической) изменчивости на примере взаимосвязи инкубационного периода, а также других репродуктивных показателей, у T. wolteri с географической широтой [11].

Так, ими были высказаны предположения об увеличении сроков инкубации при продвижении с севера на юг. Полученные нами данные по продолжительности инкубации яиц у T. wolteri противоречат их результатам. Зафиксированные нами сроки инкубационного периода - 42-44 дня - превышают значения по этому параметру, полученные нашими зарубежными коллегами для самок T. wolteri, собранных в двух провинциях КНР и помещенных в условия, аналогичные с нашими. Для самок из провинции Хэйлунцзян сроки инкубации составили - 36-37 дней, а для популяции этого вида из провинции Аньхой, расположенной в более низких широтах, - 4142 дня [11]. Существует и другое исследование, выполненное в Республике Корея. В нем указывается, что период полного развития яиц для T. wolteri из популяции, обитающей на о. Чечжу, составил 18-20 дней [12], что отличается от результатов работ других исследователей и наших наблюдений. Следует отметить, что в вышеуказанной публикации отсутствуют сведения по температурному режиму, и это не позволяет использовать её данные для исследований по клинальной изменчивости. Таким образом, требуется дальнейшее проведение экспериментальных работ для прояснения наличия связи между сроками инкубационного периода T. wolteri и географической широтой.

Исходя из литературных и наших данных по размножению T. wolteri, мы попытались найти различия в репродуктивной стратегии исследуемых ящериц в зависимости от географической широты обитания по другому параметру. Полученное L. Luo et al. среднее количество яиц в кладке $(2,8 \pm 0,1)$ для провинции Аньхой (КНР) [10] отличается от подсчитанного нами $-6,0 \pm 1,0$ яиц - более чем вдвое. Это связано, на первый взгляд, с большим размером тела самок, собранных на территории Приморского края (Россия) 54,7 мм, по сравнению с размерами ящериц с более южных территорий (КHP) - 51,9 мм по L. Luo et al. [10]. На зависимость размера ящериц от населяемой ими широты также указывали B.-J. Sun с соавторами [11]. Они сравнивали размеры ящериц, обитающих на юге и на севере Китая (51,9 мм и 55,35 мм соответственно).

Но количество яиц в кладке обусловлено также особенностями среды обитания. Растянутое созревание яиц у T. wolteri в районах с более теплым климатом позволяет самкам делать несколько (до пяти) кладок за сезон [10], тогда как пониженные температуры северных широт приводят к уменьшению сроков репродуктивного сезона и, как следствие, к сокращению количества кладок, откладываемых за теплый период, с одновременным увеличением количества яиц в одной кладке.

Мы предполагаем, что возможно проявление корреляции размера тела вылупившихся сеголеток с широтой обитания этого вида. Среднее значение длины тела сеголеток T. wolteri - 21,8 мм (n=?), полученное B.-J. Sun et al. [11], ниже наших данных 22,7 мм (n=7), то есть наблюдается уменьшение размеров тела при перемещении с севера на юг. Это 64 предположение требует дальнейшей проверки, в связи с тем, что в упомянутой работе B.-J. Sun et al. из некоторых кладок сеголетки не вышли, и также не указано количество промеренных сеголеток. В нашем же случае выборка недостаточно достоверна изза малого количества материала.

B paботе S. Takenaka [7], где приводятся сведения по кладкам и сеголеткам T. amurensis с о. Цусима (Япония), указывается, что среднее количество яиц в одной кладке этого вида составляет 4 яйца, тогда как для территории Приморского края (Россия), расположенного значительно севернее Цусимы, этот показатель равен 5,2. Так как в работе S. Takenaka [7] рассматривались только две кладки T. amurensis, полагаем, что ещё рано делать окончательные выводы о зависимости вышеуказанного параметра репродуктивности от широты. Для T. wolteri среднее количество яиц в одной кладке для территории России составляет 6 яиц, а для провинции Аньхой (Китай) 2,8 [10], что согласуется с предположением, выдвинутым китайскими коллегами о зависимости репродуктивности T. wolteri от географической широты [11].

Для получения статистически достоверных результатов по размерному ряду яиц и сеголетков ящериц и дальнейшему изучению клинальной изменчивости на примере этой группы ящериц требуются более обширные количественные выборки Takydromus для лабораторных наблюдений, а также сбор дополнительных параметров: взвешивание самок, яиц и сеголетков, более точное измерение температуры и влажности воздуха и почвы в инкубаторе.

В ходе лабораторных исследований были уточнены данные по рациону питания обоих видов долгохвосток в условиях террариума. Ящерицам были предложены различные виды беспозвоночных табл. 3.

Из предложенных видов как T. amurensis, как и T. wolteri поедали многоножек, мучных червей, тараканов, пауков, сверчков и мух.

В результате лабораторных исследований было выявлено несколько вариантов поведения долгохвосток при поедании различных видов пищи. Эти опыты проводились на двух особях T. amurensis и трех T. wolteri. Фиксировались следующие варианты: 1 при поедании паука долгохвостка, схватив его, на некоторое время замирает, затем бросает свою добычу, снова хватает, трясет и съедает; 2 - при поедании многоножек ящерица ловит их и сразу заглатывает; 3 - поймав муху, ящерица очень долго трясет добычу и только после этого съедает.

Пищевое поведение для обоих видов выглядело одинаково, без видимых различий. Следует отметить, что они были отловлены с совместных зон обитания (окрестности г. Арсеньев).

Было отмечено, что сеголетки T. amurensis активно принимали пищу с первого дня после выхода из яиц. Их рацион составляли пауки размером 2-3 мм. Через два дня мы начинали давать им мух размером 6-7 мм.

Согласно литературным источникам [4-6; 8; 12], в условиях террариума Takydromus поедают мокриц, мух, тараканов и червей. Среди насекомых Ю.М. Коротков [6] указывает на присутствие в рационе ящериц представителей отряда прямокрылых и жесткокрылых. Тем не менее наш эксперимент показал, что 
T. amurensis и T. wolteri отказались поедать мокриц, червей, стафилинид и муравьев. K.-S. Коо и Н.-S. Oh [12] в своей работе также показали, что в рацион T. wolteri не входят муравьи, земляные черви и жуки.

Таблица 3 - Избирательность T. amurensis и T. wolteri при выборе пищевых объектов

\begin{tabular}{|c|c|c|}
\hline Вид пищи & T. amurensis & T. wolteri \\
\hline $\begin{array}{l}\text { Дождевые черви } \\
\text { Отр. Lumbricomorpha } \\
\text { Сем. Lumbricidae }\end{array}$ & - & - \\
\hline $\begin{array}{l}\text { Многоножки } \\
\text { Класс Chilopoda } \\
\text { Отр. Geophilomorpha } \\
\text { Отр. Lithobiomorpha }\end{array}$ & + & + \\
\hline $\begin{array}{l}\text { Мокрицы } \\
\text { Отр. Isopoda } \\
\text { Подотр. Oniscidea }\end{array}$ & - & - \\
\hline $\begin{array}{l}\text { Пауки } \\
\text { Отр. Aranei }\end{array}$ & + & + \\
\hline $\begin{array}{l}\text { Муравьи } \\
\text { Oтр. Hymenoptera } \\
\text { Сем. Formicidae }\end{array}$ & - & - \\
\hline $\begin{array}{l}\text { Стафилиниды } \\
\text { Отр. Coleoptera } \\
\text { Сем. Staphylinidae } \\
\end{array}$ & - & - \\
\hline $\begin{array}{l}\text { Личинки мучного хрущака } \\
\text { Отр. Coleoptera } \\
\text { Сем. Tenebrionidae (larva) } \\
\end{array}$ & + & + \\
\hline $\begin{array}{l}\text { Мухи } \\
\text { Отр. Diptera } \\
\text { Сем. Muscidae }\end{array}$ & + & + \\
\hline $\begin{array}{l}\text { Тараканы } \\
\text { Отр. Blattodea } \\
\text { Сем. Ectobiidae }\end{array}$ & + & + \\
\hline $\begin{array}{l}\text { Сверчки } \\
\text { Отр. Orthoptera } \\
\text { Сем. Gryllidae }\end{array}$ & + & + \\
\hline
\end{tabular}

Примечание. «+» - предпочтительный источник пищи; «-»- неудовлетворительный источник пищи.

Мы смогли уточнить данные А.П. Павлова, который писал, что прежде чем заглотить пищу, ящерицы довольно долго ее трясут [4]. Он предполагал, что это связано с крупными размерами добычи и таким образом они разрывают ее на части. Мы отметили, что при равных размерах разная добыча (паук, муха, таракан, многоножка) поедается по-разному. Первые три объекта поглощаются после долгого встряхивания, тогда как многоножка каждый раз заглатывалась сразу. Возможно, здесь ключевым моментом является более удобная форма пищи для заглатывания, а не общий ее размер.

Не подтвердилось предположение U. Schluter [8, c. 44] о том, что в первые три дня сеголетки Takydromus ничего не едят. В нашем эксперименте сеголетки T. amurensis принимали пищу уже через 23 часа после выхода из яиц.

\section{Выводы}

В работе представлены новые сведения об отдельных аспектах размножения и питания двух малоизученных видов ящериц рода - Takydromus: Takydromus wolteri u Takydromus amurensis - в север- но-восточной части их ареала (Приморский край, Дальний Восток, Россия).

Впервые в природе зафиксирована совместная кладка нескольких самок T. amurensis - 30 яиц.

Впервые приводятся данные по срокам инкубационного периода для российских популяций этих видов: у T. amurensis - 44-56 дней, у T. wolteri - 4244.

Отмечены более ранние, чем указывалось в литературных источниках, сроки выхода из яиц сеголеток T. wolteri - середина второй декады августа.

Рассматриваются вопросы клинальной изменчивости по отдельным морфометрическим и репродуктивным параметрам. Полученные данные по продолжительности сроков инкубации яиц у T. wolteri противоречат предположению китайских исследователей об увеличении сроков инкубации T. wolteri при продвижении с севера на юг. Среднее количество яиц в кладке T. wolteri более чем в два раза больше показателей по этому параметру для провинции Хейлунцзян (КНР). Предполагается, что, так как пониженные температуры северных широт приводят к уменьшению сроков репродуктивного сезона и, как следствие, к сокращению количества кладок, откладываемых за теплый период, одновременно происходит увеличение количества яиц в каждой кладке. Требуются дальнейшие, более глубокие и детальные лабораторные исследования по этой теме.

Выявлено, что T. wolteri u T. amurensis в лабораторных условиях выбирают в качестве корма беспозвоночных из следующих отрядов и семейств: Aranei, Geophilomorpha, Lithobiomorpha, Tenebrionidae (larve), Muscidae, Ectobiidae и Gryllidae.

Приводятся новые сведения по пищевому поведению в условиях террариума. Оба вида используют различные приемы умерщвления и поедания добычи в зависимости от того, к какой группе беспозвоночных она относится. Возможно, ключевым моментом при выборе формы поведения является тип конфигурации пищевого объекта для заглатывания, а не общий ее размер.

Экспериментальным путем доказано, что сеголетки T. amurensis могут принимать пищу уже через 2-3 часа после выхода из яиц.

Выражаем глубокую благодарность М.В.Акуленко за иенную информацию по долгохвосткам, Ю.Е. Дочевому и А.С. Портнягину за помощь при проведении полевых исследований.

\section{СПИСОК ЛИТЕРАТУРЫ:}

1. Arnold E.N. Interrelationships and evolution of the East Asian grass lizards, Takydromus (Squamata: Lacertidae) // Zool. J. Linn. Soc. 1997. Vol. 119. P. 267-296.

2. Ананьева Н.Б., Боркин Л.Я., Даревский И.С., Орлов Н.Л. Земноводные и пресмыкающиеся. Энциклопедия природы России. М.: АВF, 1998. С. 410411.

3. Маслова И.В. Корейская долгохвостка в заповеднике «Ханкайский» // Материалы III съезда Герпетологического общества им. А.М. Никольского. СПб., 2008. С. 281-285.

4. Павлов П.А. Животный мир Маньчжурии по коллекциям Музея Общества Изучения Маньчжурского Края (пресмыкающиеся и земноводные) // Вестник Маньчжурии. 1926. № 8. С. 1-23. 
5. Коротков Ю.М. Материалы по экологии амурской долгохвостки Tachydromus amurensis Peters // Фауна и экология наземных позвоночных юга Дальнего Востока СССР. Владивосток: ДВНЦ АН СССР, 1974. C. $167-171$.

6. Коротков Ю.М. Наземные пресмыкающиеся Дальнего Востока. Владивосток: Дальневосточное книжное изд-во, 1985. 133 с.

7. Takenaka S. Reproductive ecology of Japanese lacertid lizards // Current Herpetology in East Asia / M. Matsui, T. Hikida and R.C. Gorris (eds.). Kyoto: Herpetol. Soc. Jpn, 1989. P. 364-369.

8. Schluter U. Die Langschwanzeidechsen der Gattung Takydromus. Kirschner\&Seufer Verlag. Germany. 2003. $110 \mathrm{p}$.

9. Маслова И.В. Особенности поведенческих реакций на источник опасности у корейской долгохвостки Takydromus wolteri (Fischer, 1885) // Научные исследования в заповедниках Дальнего Востока: матер. VI Дальневост. конф. по заповедному делу. Ха- баровск. 15-17 октября 2003 г. Хабаровск: ИВЭП ДВО РАН, 2004. Ч. 2. С. 3-4.

10. Luo L., Wu Y., Zhang Z., Xu X. Sexual size dimorphism and female reproduction in the white-striped grass lizard Takydromus wolteri // Current Zoology. 2012. Vol. 58 (2). P. 236-243.

11. Sun B.-J., Li S.-R., Xu X.-F., Zhao W.-G., Luo L.-G., X. Ji, Du W.-G. Different mechanisms lead to convergence of reproductive strategies in two lacertid lizards (Takydromus wolteri and Eremias argus) // Oecologia. 2013. Vol. 172. P. 645-652.

12. Koo K.-S., Oh H.-S. Biological Characteristics of Takydromus wolteri (Squamata: Lacertidae) Living on Jeju Island // Education, science and investigations. 2013. Vol. 15. P. 13-21.

13. Бродский А.К., Гейспиц К.А., Гринфельд Э.К., Кузнецова И.А., Мартынова Е.Ф., Саулич А.Х., Стекольников Л.А., Тыщенко В.П. Краткий определитель отрядов и семейств наземных членистоногих европейской части СССР. Л.: Изд-во ЛГУ, 1974. 104 с.

\section{INDIVIDUAL ASPECTS OF TAKYDROMUS WOLTERI AND TAKYDROMUS AMURENSIS BIOLOGY}

(C) 2017

Portniagina Ekaterina Yurievna, postgraduate student of Ecology Department Far Eastern Federal University (Vladivostok, Russian Federation)

Maslova Irina Vladimirovna, candidate of biological sciences, leading engineer of Theriology Laboratory Federal Scientific Center of the East Asia Terrestrial Biodiversity of Far Eastern Branch of Russian Academy of Sciences (Vladivostok, Russian Federation)

Abstract. The paper presents information regarding specific aspects of reproduction and nutrition of two poorly studied lizard species of genus Takydromus (Takydromus wolteri and Takydromus amurensis) in the north-eastern part of their habitat (Primorskiy Krai, Far East, Russia). The material given in the publication was collected both in natural and laboratory conditions. Data related to quantity as well as size of eggs and juveniles (right after their birth) are presented. The joint clutch of several female of T. amurensis was found for the first time and contained 30 eggs. For the first time the incubation period has been reported for these species that inhabit Russian territory (T. amurensis - 44-56 days, T. wolteri-42-44). Date of escape from eggs has been revealed for T. wolteri to be earlier than given in literature and occur on second decade of August. Cline dependence of morphometric and reproductive parameters have been dealt. Both species have been shown to prefer the following invertebrates as meal in lab conditions - Aranei, Geophilomorpha, Lithobiomorpha, Tenebrionidae (larve), Muscidae, Ectobiidae и Gryllidae. New information regarding nutritional behavior is provided for T. wolteri and T. amurensis in terrarium conditions. Both species use various traits to kill and to eat the catch based on the group to which the invertebrate is related. It has been shown empirically that juveniles of $T$. amurensis can eat meal right in 2-3 hours after their escape from the eggs.

Keywords: Lacertidae; Takydromus wolteri; Takydromus amurensis; peculiarities of reproduction; lab incubation; incubation period; egg size; quantity of eggs; juveniles quantity; cline dependence; nutritional behavior; nutritional selectivity; Primorskiy Krai; Far East; Russia.

УДК 574

Статья поступила в редакцию 05.10.2017

\section{ВОССТАНОВЛЕНИЕ НАСЕЛЕНИЯ ПТИЦ В СОСНОВЫХ ЛЕСАХ ПОСЛЕ КАТАСТРОФИЧЕСКИХ ПОЖАРОВ 2010 ГОДА}

(C) 2017

Сорокина Юлия Александровна, аспирант кафедры ботаники и зоологии

Борякова Елена Евгеньевна, кандидат биологических наук, доцент кафедры ботаники и зоологии Национальный исследовательский Нижегородский государственный университет им. Н.И. Лобачевского (г. Нижний Новгород, Российская Федеращия)

Аннотация. В данной статье рассматриваются проблемы восстановления населения птиц после пожаров. Исследования проходили в двух природных заповедниках: «Керженский» и «Мордовский», располагающихся в северной и южной частях нижегородского Поволжья соответственно. В данных ООПТ антропогенные воздействия сведены к минимуму, что позволяет судить о ходе восстановления населения птиц в эталонных условиях. Учеты проведены как в затронутых пожарами территориях заповедников, так и на контрольных участках. В работе представлены результаты учетов птиц спустя пять лет после пожара. Наше исследование показало динамику восстановления сообщества птиц после пожаров и ее зависимость от возраста и истории 